\title{
A genome-wide scan to locate regions associated with familial vesicoureteral reflux
}

\author{
ZSUZSA BARTIK $^{1}$, ULLA SILLÉN ${ }^{1}$, MALIN ÖSTENSSON ${ }^{2}$, SUSANNE FRANSSON $^{3}$, \\ ANNA DJOS $^{3}$, ROSMARIE SJÖBERG ${ }^{3}$, TOMMY MARTINSSON ${ }^{3}$ \\ ${ }^{1}$ Department of Pediatric Surgery, Pediatric Uronephrology Center, The Queen Silvia Children's Hospital, \\ Institute of Clinical Sciences, Sahlgrenska Academy, University of Gothenburg, SE-41685 Gothenburg; \\ ${ }^{2}$ Bioinformatics Core Facility, Sahlgrenska Academy, University of Gothenburg; \\ ${ }^{3}$ Department of Laboratory Medicine, Institute of Biomedicine, Sahlgrenska Academy, \\ University of Gothenburg, SE-40530 Gothenburg, Sweden
}

Received February 7, 2021; Accepted July 6, 2021

DOI: $10.3892 /$ etm.2021.11015

\begin{abstract}
Vesicoureteral reflux (VUR) is a congenital malformation carrying a high risk of recurrent urinary tract infections (UTI) and, at worst, chronic renal failure. Familial clustering implies a genetic etiology, but studies during the past few decades have demonstrated a causal gene variant in $<10 \%$ of patients with VUR. The aim of the present study was to search for fully or partially shared ancestral haplotypes in 14 families from south-western Sweden with at least three affected members. High-density single nucleotide polymorphism microarray was used for genotyping prior to analysis with a compatibility matching method developed in-house, and the analysis of copy number variations (CNV). No single unique haplotype was revealed to be shared by the families, thereby excluding a common ancestry and founder mutations as a probable cause of VUR. After evaluation of haplotypes shared by subsets of families, a haplotype shared by nine families was found to be of particular interest. This haplotype, located at chromosomal region $4 \mathrm{q} 21.21$, harbours two tentative candidate genes (bone morphogenetic protein 3 and fibroblast growth factor 5), both expressed in metanephros and with known functions during nephrogenesis. As to CNV, only one family had a specific CNV shared by all affected members. This was a focal deletion at $5 q 31.1$ including follistatin-like 4 , a gene without a previous known connection to VUR. These data demonstrated the genetic heterogeneity of VUR and
\end{abstract}

Correspondence to: Professor Ulla Sillén, Department of Pediatric Surgery, Pediatric Uronephrology Center, The Queen Silvia Children's Hospital, Institute of Clinical Sciences, Sahlgrenska Academy, University of Gothenburg, 10 Rondvägen, SE-41685 Gothenburg, Sweden

E-mail: ulla.sillen@gu.se

Key words: vesicoureteral reflux, heredity, genome-wide association studies, single nucleotide polymorphism, haplotype sharing, DNA copy number variations indicated that an interaction of environmental and genetic factors, including non-coding and epigenetic regulators, all contribute to the complexity of VUR.

\section{Introduction}

Vesicoureteral reflux (VUR) is a common urinary tract (UT) defect that occurs in approximately $1-2 \%$ of young children (1). High-grade VUR is seen primarily in male infants and is often associated with generalised renal damage, i.e. renal hypodysplasia. This rare condition is regarded as a congenital abnormality associated with primary VUR (2). Overall, in children with VUR the most common form of renal damage is a focally acquired injury caused by ascending urinary tract infections (UTI) (3). The morbidity seen in children with VUR is often related to recurrent UTI, which carries the risk of progressive renal damage.

Familial clustering of VUR is well recognized. The risk that offspring of affected individuals will have reflux themselves has been reported to be as high as $66 \%$, while the risk of a sibling of an affected individual also having the condition is between 27 and 51\% (4-7). The high frequency of VUR in relatives favours an autosomal dominant inheritance pattern with reduced penetrance (8-12), although some studies indicate possible autosomal recessive inheritance (13) or an X-linked mode of inheritance (14).

The search for a single gene linked to the heritability of VUR has so far been unsuccessful, but a large number of candidate genes have been suggested. These candidates mainly include genes functioning in the developmental pathways of the kidney, ureter and ureterovesical junction. During the last decade, the VUR hypodysplasia anomaly has been included in the congenital anomalies of the kidney and urinary tract (CAKUT) group, which comprises a broad spectrum of renal and lower UT structural and functional abnormalities. The rationale for this approach is the shared embryological background, starting with an interaction between the ureteric bud (UB) and metanephric mesenchyme (MM) $(15,16)$. There has been a rapid increase in identification of CAKUT-associated genes due to recent advances in new and more affordable 
sequencing. Mutations in numerous different developmental genes have been identified, but there is little correlation between families and individuals. Despite this progress, the mutations responsible for the majority of CAKUT conditions remain unknown $(17,18)$.

The vast majority of genetic studies of VUR and/or CAKUT have focused on the coding part of the genome. However, in numerous studies of familial VUR there is a relative paucity of precise genetic causes, despite indications of a dominant autosomal inheritance pattern. It may therefore be reasonable to expect that VUR-related variants are located in the non-coding DNA, such as the promotor, topologically associating domain (TAD) boundaries, or regulatory elements. Studies have shown that the regulatory elements can be located within the gene, or located at a distance of up to $1 \mathrm{Mb}$ from the gene (19). Thus, designating variants in non-coding areas as pathological is far more difficult than identifying variants in protein-coding genes. Whole-genome scans to identify common regions are the first step towards locating these regulatory regions. However, genome scan studies, mainly linkage analyses, show different results with very few shared genomic regions among hereditary VUR patients.

Besides single nucleotide variants (SNV) and smaller insertions/deletions (indels), copy number variations (CNV) are also important contributors to human genetic variation. However, some CNVs can also be associated with a variety of birth defects and common diseases (20). CNV-associated congenital malformations depend on the disruption of specific genes at breakpoints, and also on which genes are located within the duplication or deletion. Few studies have investigated the impact of CNV in relation to VUR/CAKUT $(21,22)$.

For this study we included only families from the south-western part of Sweden who had the VUR complex (same phenotype). This was because of the higher levels of heredity in VUR than in other conditions included in CAKUT. We concentrated on individuals who had the highest grade of VUR together with renal hypodysplasia, which is the most severe phenotype. In this study we explored the possible presence of shared chromosomal areas (haplotypes) in 14 families with familial VUR. We screened for unique haplotypes which might be shared by affected individuals in the families and would therefor indicate a common ancestor. Screening was performed using high-density single nucleotide polymorphism (SNP) arrays, followed by genome-wide association (GWA) and the SNP compatibility matching method recently described $(23,24)$. As VUR appears to be a genetically heterogeneous disease we also evaluated shared haplotypes, including those in subsets of families, for coding and non-coding genes which could cause the VUR abnormality. In addition, we searched for CNVs which might be associated with the condition.

\section{Materials and methods}

Patients and families. Fourteen families with three or more members with primary VUR, were recruited at Queen Silvia Children's Hospital (a tertiary referral center) in Gothenburg, Sweden. The families were contacted and information on the study was given. Before entering the study all subjects and/or their parents signed informed consent forms for genetic screening. Blood samples or buccal smear (Isohelix SK-2S Buccal Swabs) specimens were collected using standard procedures. The Regional Ethical Review Board in Gothenburg approved the study (Dnr 589-05).

A total of 43 patients in 14 families with VUR were included (49\% males). To clarify the relationship and analyse the pattern of inheritance, pedigrees were constructed for each family (Fig. 1). Additional members of the families whose medical histories strongly suggested VUR, but who had not undergone radiological investigations, were classified as probable cases. Patients with VUR secondary to a neurogenic bladder and posterior urethral valves were excluded from the study.

Clinical data were obtained from medical records. A VUR grade was obtained from a voiding cystourethrography (VCUG), levels of kidney damage from dimercaptosuccinic acid (DMSA) or mercaptoacetyltriglycine (MAG-3) scintigraphy (25), and total kidney function was measured using glomerular filtration rate (GFR) or was estimated according to the Schwartz formula (26). When patients had bilateral VUR, their more severely affected side was measured to establish VUR grade and kidney damage. Focal kidney damage was defined as one or more areas with reduced uptake or indentation of the renal outline, and is caused by postnatally acquired renal scarring (3). Generalised damage, referred to as congenital renal hypodysplasia, was classified as a small kidney with reduced tracer uptake or a diffuse parenchymal anomaly. A GFR of $<80 \%$ ( $<2 \mathrm{SD})$ of expected GFR was considered subnormal (27).

SNP genotyping. Genomic DNA was extracted from blood lymphocytes (in 25 cases) and buccal cells (in 15 cases) using a Qiagen DNeasy Blood and Tissue Kit (Qiagen) and a Maxwell 16 Buccal Swab LEV DNA Purification Kit (Promega, Corp.) respectively. For three individuals from three different families DNA samples were not available. The samples were genotyped on Affymetrix 250K SNP NspI arrays, (Affymetrix Inc.), which detects 262,000 SNPs. The array experiments were performed either locally $(n=34$, Department of Laboratory Medicine at the University of Gothenburg, Gothenburg, Sweden) or at the BEA Core Facility, ( $n=6$, Karolinska Institute, Huddinge, Sweden), according to the manufacturer's protocol (Affymetrix). Briefly, $250 \mathrm{ng}$ of genomic DNA was digested using the NspI restriction enzyme and ligated to adaptors. After ligation, the template was subjected to PCR amplification using a generic primer that recognised the adaptor sequence. The amplified DNA was fragmented with DNase I, labelled with biotin and hybridised to a GeneChip ${ }^{\circledR}$ Human Mapping $250 \mathrm{~K}$ array. The hybridised probes were washed using the Affymetrix Fluidics Station 450 and marked with streptavidin-phycoerythrin. The arrays were scanned using a confocal laser scanner, GeneChip Scanner 3000 (Affymetrix). Primary data analysis was performed using GDAS (GeneChip ${ }^{\circledR}$ DNA Analysis software) and GTYPE (Affymetrix) for the extraction of genotype calls.

SNP compatibility matching. SNP genotype data for individuals were analysed using SNP compatibility matching $(23,24)$. This method can be applied to dominant traits in families where several members are affected. In the original SNP compatibility matching method, it was assumed that all 

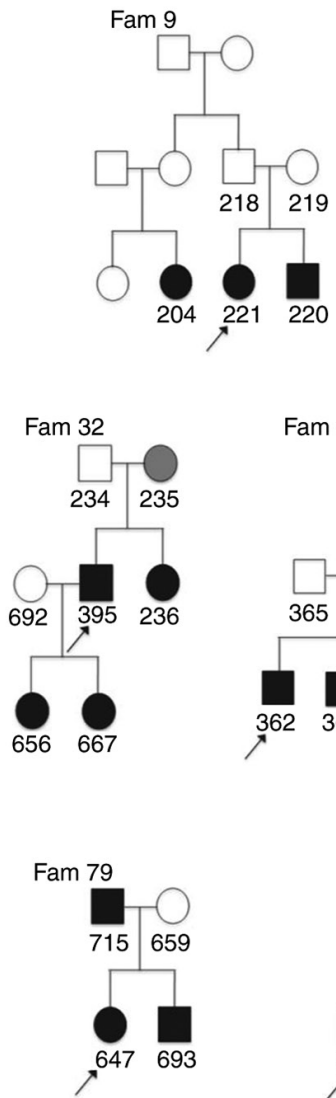
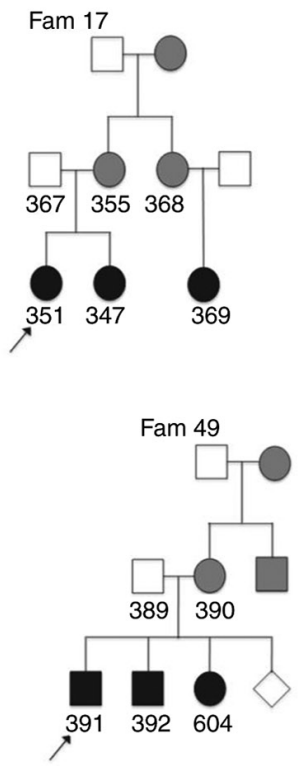
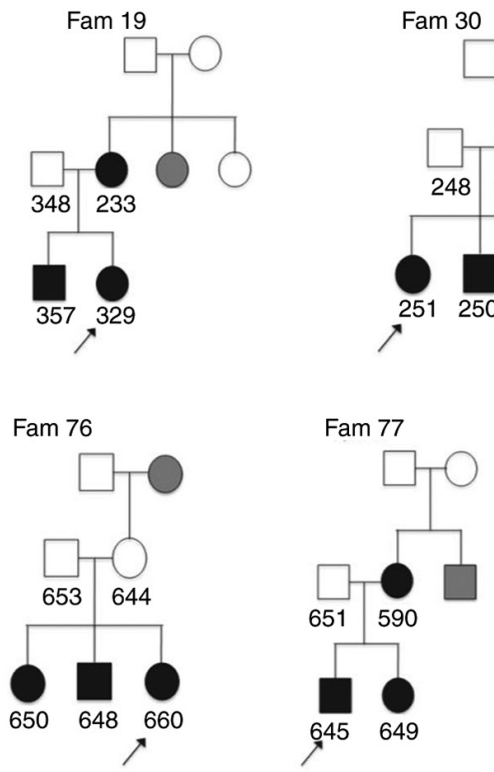

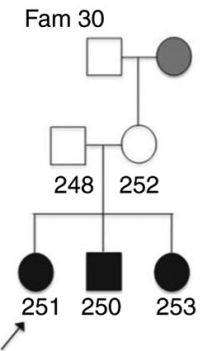

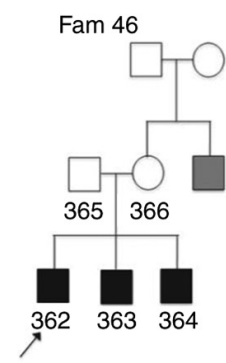
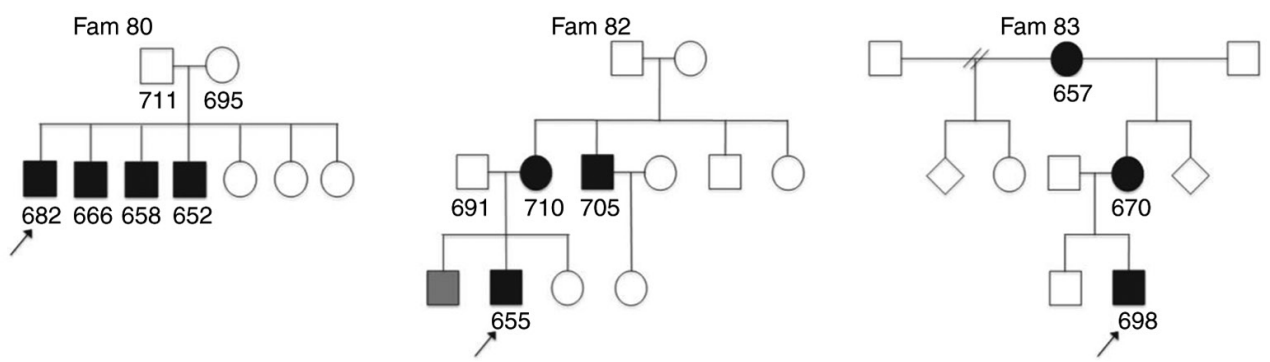

Figure 1. Pedigrees describing the 14 participating families with three or more vesicoureteral reflux cases. Squares, males; circles, females; rhombuses, sex unknown; black symbols, indicate diagnosis confirmed by voiding cystourethrography; grey symbols, indicate strong history of VUR but no available radiological investigations; crossed over symbols, deceased; arrow, index cases. VUR, vesicoureteral reflux.

affected individuals had a common ancestor and shared the causal IBD (identical by descent) variant. Although it was unlikely that all affected individuals in our 14 families shared the same ancestral variant, we still wanted to examine this possibility. In a similar way to homozygosity mapping we also used this method to identify shared haplotypes, which may act as causal factors for a disease, in different subsets of affected subjects or families. The aim of the method is to identify regions free from incompatibilities. For each SNP locus, individuals can have either genotype 'AA', 'AB' or 'BB'. A locus where at least one affected individual is ' $A A$ ' and at least one other affected individual is ' $\mathrm{BB}$ ' is scored as an incompatibility. A locus of this type cannot by definition be included in the disease gene haplotype we are trying to locate. However, a continuous large region of SNP loci, without any incompatibilities among affected individuals, may include a unique disease haplotype and, consequently, also the disease gene. Genotypes for our 14 affected families were compared and incompatibilities, as defined above, for all the 260,000 SNP loci were scored and plotted against the genome position for each locus. Corresponding genotype data generated by the Affymetrix $250 \mathrm{~K}$ array in four healthy control individuals were entered into the analysis. Given that an affected individual and an unaffected control do not have the same disease phenotype, their DNA must by definition be different. The regions of the genome that were identical by state (IBS) in both VUR cases and controls were therefore excluded.

Study strategies. Two different strategies were used for analysing the study group and the controls (Fig. 2). In the first set of analyses, we tested whether the disease haplotype was inherited from a common familial ancestor (causal variant IBD). For this strategy we included one affected individual per family, since a common ancestor hypothesis presumes that all affected members of the family share the same haplotype, which contains the founder gene mutation. We used four controls added one at a time. Haplotypes found in both the control and the families were excluded as a non-specific disease haplotype. If the haplotype region shared by affected individuals, on the other hand, became covered with incompatibilities when the control data was added, this indicated that the haplotype was not present in the control and thus might be specific to the disease. After testing the controls one after the other, the shared region(s) that remained could be regarded as identical by reason of descent. In these analyses the size of haplotype regions we chose was $\geq 120$ SNPs. After this, in a second set of analyses, we searched for common haplotype regions in subsets of families. All affected individuals from each family were included and for each family only haplotypes shared by all family members were selected. We used four 


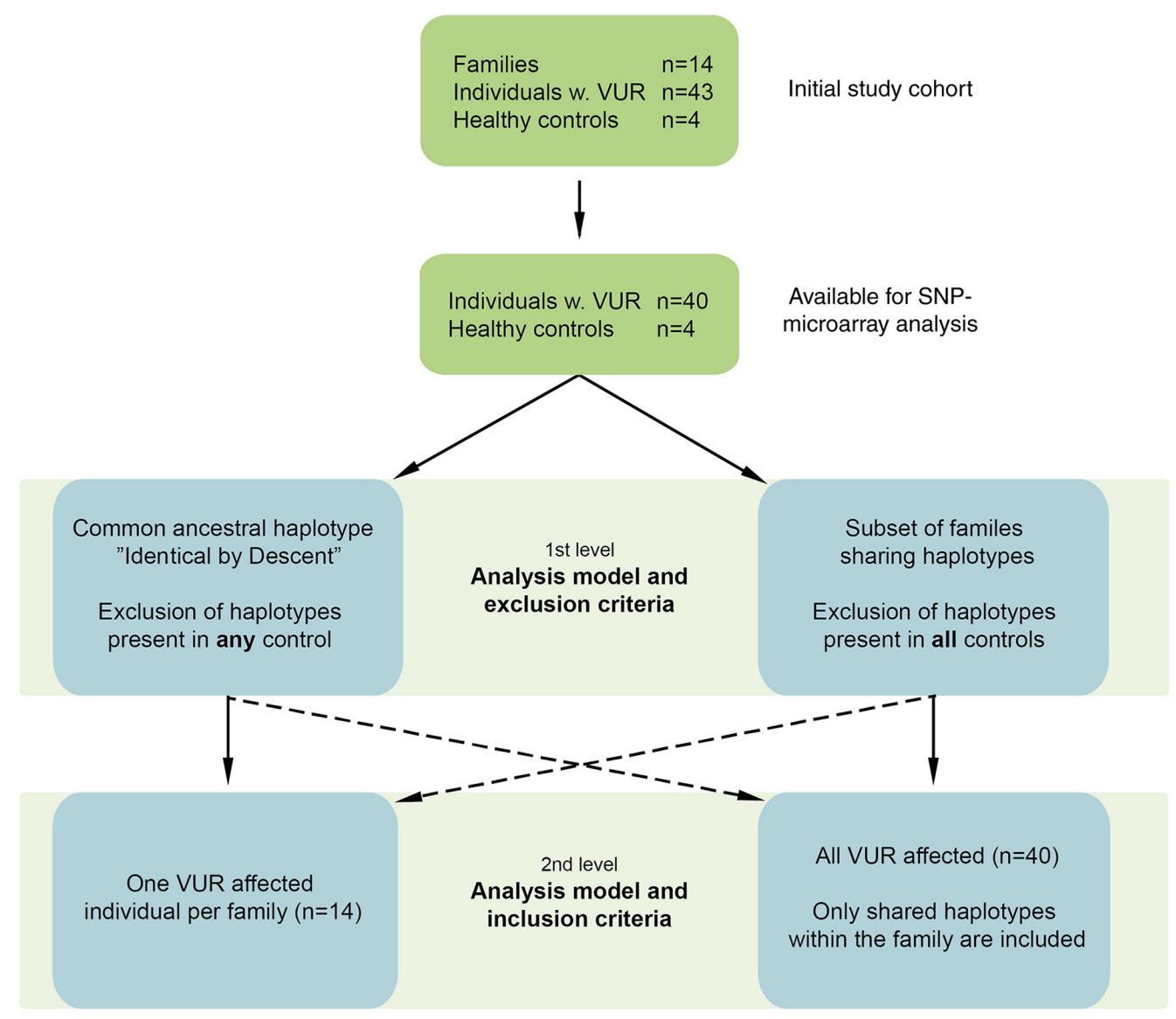

Figure 2. Flow chart of genome-wide scan to locate candidate regions for familial VUR. Dashed arrows indicate that the results are not presented for the indicated combination of study group and controls. VUR, vesicoureteral reflux; w., with; SNP, single nucleotide polymorphism.

controls to rule out common haplotypes within the general population. We excluded only those regions that were identical for VUR cases and all four controls. The haplotype region unique to the affected families and not present in all four controls could be regarded as specific to the disease. Given the limited number of families available for this study, a less stringent filtering strategy was used with inclusion of a very restricted number of controls in order to only exclude the most common haplotypes i.e. haplotypes shared by all four controls. With this strategy, increase in number of controls would probably mean exclusion of fewer common haplotypes. The chosen size of haplotype regions was $\geq 60$ SNPs in the second set of analyses.

CNV detection. The R package 'aroma.affymetrix' was used for copy number detection. The CEL files for each sample provided us with copy number estimates of the intensity values using the CRMA v2 method (28). For copy number segmentation we used the Circular Binary Segmentation (CBS) method (29). Criteria for inclusion of CNVs were: i) number of SNPs per $\mathrm{CNV} \geq 10$; ii) $\mathrm{CNV}$ size $>50 \mathrm{~kb}$ but $<3 \mathrm{Mb}$; iii) $\mathrm{CNV}$ frequency $<1 \%$ in the general population. The CNVs were also filtered by the $\log 2$ values, excluding those between $+/-0.2$. We searched for recurrent identical CNVs within families. CNVs were defined as identical if they had the same state of duplication or deletion, showed $\leq 30 \%$ difference in length, and overlapped by $>70 \%$.
Data bases. All genomic positions for SNPs and CNVs are given relative to GRCh37/hg19 genome assembly. Regions shared by seven families or more were reported in the results. The UCSC genome browser (https://genome.ucsc.edu) was used to visualise the regions which could theoretically contain the disease gene. We recorded the genes, both coding and non-coding DNA sequences, in these regions. In addition, we examined their expression and role during kidney development using GUDMAP (the GenitoUrinary Development Molecular Anatomy Project data; https://www.gudmap.org) and via an extensive literature search (https://www.ncbi.nlm. nih.gov/pubmed). The significance of each CNV detected was determined by comparison with public CNV databases: DECIPHER (Database of Chromosomal Imbalance and Phenotype in Humans using Ensembl Resources, https://decipher.sanger.ac.uk/) and DGV (Database of Genomic Variants, http://dgv.tcag.ca/dgv/app/home).

\section{Results}

Clinical characteristics. The study included 43 patients with VUR, from 14 different families (21 males). Two families were nuclear and 12 were extended families. The relationship between the affected individuals and the pattern of inheritance is shown in pedigrees in Fig. 1. Phenotypical details of the study subjects are outlined in Table I. Of the 43 patients with VUR, high-grade reflux (grades IV to V) was seen in $49 \%$, 
Table I. Demographic data, VUR grades, renal abnormalities and function for the group of individuals included in the IBD part of the study and for the whole study group.

\begin{tabular}{|c|c|c|}
\hline Characteristics & IBD study cohort ${ }^{\mathrm{a}}, \mathrm{n}=14(\%)$ & Total VUR cohort, $\mathrm{n}=43(\%)$ \\
\hline \multicolumn{3}{|l|}{ Sex } \\
\hline Female & $6(43)$ & $22(51)$ \\
\hline Male & $8(57)$ & $21(49)$ \\
\hline \multicolumn{3}{|l|}{ Presenting symptom VUR } \\
\hline Pyelonephritis & $9(64)$ & $29(68)$ \\
\hline Pre- and postnatal screening & $3(22)$ & $10(23)$ \\
\hline Other symptoms & $2(14)$ & 4 (9) \\
\hline Age at presentation, months & $11(0.25-98)$ & $7(0.25-98)$ \\
\hline \multicolumn{3}{|l|}{ Grade of reflux } \\
\hline I-III & $4(29)$ & $22(51)$ \\
\hline IV-V & $10(71)$ & $21(49)$ \\
\hline \multicolumn{3}{|l|}{ Uni- or bilateral reflux } \\
\hline Unilateral & $4(29)$ & $17(40)$ \\
\hline Bilateral & $10(71)$ & $26(60)$ \\
\hline \multicolumn{3}{|l|}{ Recurrent UTIs } \\
\hline No & $4(29)$ & $13(32)$ \\
\hline Yes & $10(71)$ & $28(68)$ \\
\hline \multicolumn{3}{|l|}{ Renal damage } \\
\hline No & $2(14)$ & $15(36)$ \\
\hline Yes, focal & $2(14)$ & $6(14)$ \\
\hline Yes, generalized ${ }^{b}$ & $10(72)$ & $21(50)$ \\
\hline \multicolumn{3}{|l|}{ Uni- or bilateral renal damage } \\
\hline Unilateral & $9(75)$ & $22(81)$ \\
\hline Bilateral & $3(25)$ & 5 (19) \\
\hline \multicolumn{3}{|l|}{ Total renal function } \\
\hline Normal & $10(71)$ & $34(85)$ \\
\hline Subnormal & $4(29)$ & $6(15)$ \\
\hline
\end{tabular}

${ }^{a}$ One affected individual from each family. ${ }^{b}$ Hypodysplasia. Categorical variables n (\%); continuous variables median (range). IBD, identical by descent; VUR, vesicoureteral reflux.

generalised kidney damage in $50 \%$ and subnormal total renal function in $15 \%$ of the cases. Five cases displayed additional malformations of the UT, such as bilateral duplex kidney, bladder diverticula and a unilateral megaureter. One VUR patient with syndromic presentation was diagnosed with unbalanced translocation, which was inherited from a healthy father with balanced translocation, the VUR inheritance being maternal. An additional three cases with extrarenal manifestations had syndromic features but were undiagnosed (Table SI).

The SNP compatibility matching method for locating risk regions using GWA data

GWA data testing for IBD haplotype (common ancestor). Regions with no incompatibilities were identified through SNP genotype data analyses using the method described above. One affected individual per family $(n=14)$ was included in these analyses. Since the individual chosen for the analysis was the most severely affected member of the family, this subgroup displayed more high-grade VUR (10/14), more generalised kidney damage, hypodysplasia (10/14) and more frequent subnormal total renal function (4/14) (Table I).

In these analyses we excluded shared haplotype regions in affected individuals that were also found in any of the controls, i.e. excluded as non-specific disease haplotypes. In the analyses without controls, the most frequent haplotype was present in 13 out of 14 VUR families. When tested against four healthy controls one at a time, a maximum of seven families shared one haplotype and thus the number of haplotypes shared by $\geq 7$ families decreased from 34 to only one (Table II). Thus additional controls were not included as a common ancestor haplotype already was excluded after used controls. The conclusion was that we did not find a unique haplotype that was shared by most or all the families, as the regions of interest shared by numerous families were also seen in one or more of the controls.

GWA data testing for disease variant excluding the common haplotypes. In these analyses we searched for haplotype 
Table II. Number of haplotypes shared by $\geq$ seven families in the different sets of analyses.

A, One affected individual/family

Number of haplotypes shared by $\geq$ seven of the families

Type of analysis

$\begin{array}{rcccccc}7 \text { fam } & 8 \text { fam } & 9 \text { fam } & 10 \text { fam } & 11 \text { fam } & 12 \text { fam } & 13 \text { fam } \\ 18 & 8 & 5 & 1 & 1 & 1 & 1 \\ 14 & 6 & 4 & 0 & 1 & 1 & 1 \\ 1 & 0 & 0 & 0 & 0 & 0 & 0\end{array}$

B, All affected individuals/family

Number of haplotypes shared by $\geq 7$ of the families

\begin{tabular}{|c|c|c|c|c|c|c|c|}
\hline \multirow[b]{2}{*}{ Type of analysis } & & & & & & & \\
\hline & 7 fam & 8 fam & 9 fam & 10 fam & 11 fam & 12 fam & 13 fam \\
\hline No control included & 21 & 9 & 5 & 2 & 0 & 0 & 0 \\
\hline \multicolumn{8}{|l|}{ Inclusion of 4 controls } \\
\hline Haplotypes found in all 4 controls excluded ${ }^{\mathrm{a}}$ & 20 & 6 & 5 & 1 & 0 & 0 & 0 \\
\hline Haplotypes in any of 4 controls excluded ${ }^{\mathrm{b}}$ & 0 & 0 & 0 & 0 & 0 & 0 & 0 \\
\hline
\end{tabular}

${ }^{\mathrm{a} C o m m o n}$ haplotypes in the general population. ${ }^{\mathrm{b}}$ Results not presented. Fam, families.

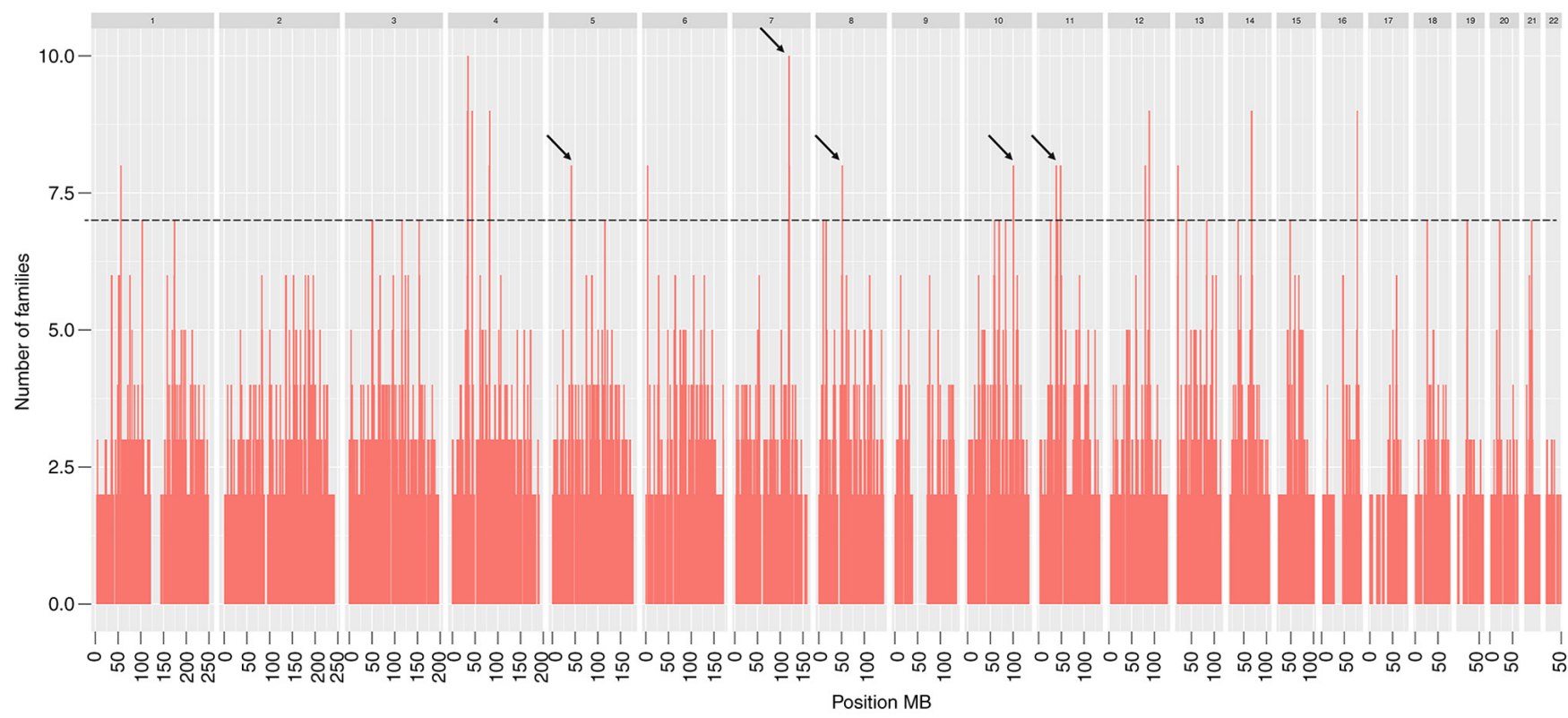

Figure 3. Genomic location of shared haplotype regions in relation to the number of families sharing the locus, with all family members included. X-axis, genomic locations on the 22 autosome chromosomes (Mb); y-axis: number of families sharing the region. There are 37 peaks at and above the horizontal dotted line, denoting the haplotype regions shared by $\geq$ seven families, before including the control data. Peaks marked with an arrow denote haplotypes that were excluded, when common haplotypes (present in all controls) were removed. The unmarked peaks show haplotypes that remained.

regions shared by subsets of VUR families, with the only exclusion being of haplotypes common in the general population, i.e. haplotypes shared by all the four controls used (Table II). Forty out of 43 affected individuals from 14 families were included in these analyses; DNA was missing from three individuals. A total of 32 haplotype regions shared by $\geq 7$ families were identified (Table III). The size of these possible disease-associated haplotypes varied from 0.20 to $1.93 \mathrm{Mb}$, with a total of $22.92 \mathrm{Mb}$, representing $0.76 \%$ of the genome. Twenty regions of haplotypes were shared by seven families, six regions by eight families and five regions by nine families, while only one haplotype was shared by 10 families (Table II). Fig. 3 illustrates the genomic locations of haplotype regions shared by $\geq 7$ families. 
Table III. Haplotype regions found in $\geq$ seven families when including all affected individuals in the 14 families, after exclusion of common haplotypes in the general population.

\begin{tabular}{|c|c|c|c|c|c|c|c|}
\hline \multicolumn{2}{|c|}{ Haplotype regions shared by $\geq$ seven families } & \multirow[b]{2}{*}{$\begin{array}{l}\text { Size of } \\
\text { region, Mb }\end{array}$} & \multirow{2}{*}{$\begin{array}{l}\text { Number of } \\
\text { families per } \\
\text { haplotype region }\end{array}$} & \multicolumn{2}{|c|}{ Genes } & \multicolumn{2}{|c|}{ Evidence } \\
\hline Genomic locations & $\begin{array}{l}\text { Cytogenetic } \\
\text { band }\end{array}$ & & & Coding & Non-coding & (Refs.) & Region \\
\hline Chr1:56,335,237-56,766,727 & $1 \mathrm{p} 32.2$ & 0.43 & 8 & 0 & - & (11) & $1 \mathrm{p} 32-33$ \\
\hline Chr1:102,757,243-103,757,081 & $1 \mathrm{p} 21.1$ & 1.0 & 7 & - & - & & \\
\hline Chr1:173,712,120-174,952,226 & $1 \mathrm{q} 25.1$ & 1.24 & 7 & - & - & (40) & $1 \mathrm{q} 23.3-\mathrm{q} 32.2$ \\
\hline Chr3:49,938,758-51,864,849 & $3 \mathrm{p} 21.31-\mathrm{p} 21.2$ & 1.93 & 7 & - & - & & \\
\hline Chr3:115,953,619-116,316,741 & $3 q 13.31$ & 0.36 & 7 & - & - & $\begin{array}{l}(40) \\
(45)\end{array}$ & $\begin{array}{l}3 \mathrm{p} 13-\mathrm{q} 21.2 \\
3 \mathrm{p} 12.3-\mathrm{q} 24\end{array}$ \\
\hline Chr3:153,425,054-153,967,763 & $3 q 25.2$ & 0.54 & 7 & - & - & (9) & 3p12.1-q26.1 \\
\hline Chr4:33,953,172-34,754,839 & $4 \mathrm{p} 15.1$ & 0.80 & 10 & 0 & - & (25) & $4 \mathrm{p} 15.1$ \\
\hline Chr4:43,274,485-43,768,843 & $4 \mathrm{p} 13$ & 0.50 & 9 & 0 & - & & \\
\hline Chr4:81,214,575-82,324,437 & $4 \mathrm{q} 21.21$ & 1.11 & 9 & $\begin{array}{l}\text { BMP3 }^{\mathrm{b}} \text {, } \\
\text { FGF5 }^{\mathrm{b}}\end{array}$ & - & & \\
\hline Chr5:115,384,247-115,845,251 & $5 \mathrm{q} 23.1$ & 0.46 & 7 & - & - & & \\
\hline Chr6:3,982,143-4,279,669 & $6 \mathrm{p} 25.2-\mathrm{p} 25.1$ & 0.36 & 8 & - & - & & \\
\hline Chr8:9,294,638-9,977,187 & $8 \mathrm{p} 23.1$ & 0.68 & 7 & $\begin{array}{l}\text { TANKS }{ }^{\mathrm{a}, \mathrm{d}}, \\
\text { SLC9A6 }^{\mathrm{a}, \mathrm{e}}\end{array}$ & - & & \\
\hline Chr8:16,029,070-16,489,054 & $8 \mathrm{p} 22$ & 0.46 & 7 & - & - & (9) & $8 \mathrm{p} 22$ \\
\hline Chr10:68,938,308-69,975,774 & $10 \mathrm{q} 21.3$ & 1.04 & 7 & - & - & (25) & $10 \mathrm{q} 21.3$ \\
\hline Chr10:83,304,656-83,757,199 & 10q23.1 & 0.45 & 7 & - & - & & \\
\hline Chr10:100,474,570-101,213,280 & $10 \mathrm{q} 24.2$ & 0.74 & 8 & - & - & & \\
\hline Chr11:26,300,178-26,592,685 & $11 \mathrm{p} 14.2$ & 0.29 & 7 & - & - & & \\
\hline Chr11:38,648,159-39,400,252 & $11 \mathrm{p} 12$ & 0.75 & 8 & 0 & - & & \\
\hline Chr11:41,769,608-42,310,568 & $11 \mathrm{p} 12$ & 0.54 & 7 & 0 & - & & \\
\hline Chr12:79,467,497-80,385,649 j & $\begin{array}{c}12 \mathrm{q} 21.2- \\
\mathrm{q} 21.31\end{array}$ & 0.92 & 8 & - & - & & \\
\hline Chr12:88,355,694-89,207,726 & $\begin{array}{c}12 \mathrm{q} 21.32- \\
\mathrm{q} 21.33\end{array}$ & 0.85 & 9 & $\begin{array}{l}\text { CEP290 }^{\mathrm{a}, \mathrm{f}} \text {, } \\
\text { KITLG }^{\mathrm{a}, \mathrm{g}}\end{array}$ & - & & \\
\hline Chr13:19,814,247-20,642,012 & $13 q 12.11$ & 0.83 & 8 & - & - & & \\
\hline Chr13:38,832,645-39,313,967 & $13 q 13.3$ & 0.48 & 7 & FREM $2^{b}$ & - & & \\
\hline Chr13:83,414,846-83,830,486 & $13 \mathrm{q} 31.1$ & 0.42 & 7 & 0 & 0 & & \\
\hline Chr14:37,462,847-38,176,041 & $\begin{array}{c}14 q 13.3- \\
\text { q21.1 }\end{array}$ & 0.71 & 7 & FOXA $1^{\text {b }}$ & $\begin{array}{c}\text { RP11- } \\
35609.2^{\mathrm{c}}\end{array}$ & & \\
\hline Chr14:66,862,743-67,886,781 & $14 q 23.3$ & 1.02 & 9 & PLEK2 ${ }^{\mathrm{a}}$ & - & & \\
\hline Chr15:48,329,542-48,925,115 & $15 \mathrm{q} 21.1$ & 0.60 & 7 & $\begin{array}{l}\mathrm{SLC} 12 \mathrm{~A} 1^{\mathrm{a}, \mathrm{h}}, \\
\mathrm{FBN}^{\mathrm{a}} \mathrm{a}, \mathrm{i}\end{array}$ & $\begin{array}{c}\text { RP1- } \\
208 \mathrm{~K} 4.1^{\mathrm{c}}\end{array}$ & & \\
\hline Chr16:78,422,926-78,621,620 & $16 \mathrm{q} 23.1$ & 0.20 & 9 & - & - & & \\
\hline Chr18:26,268,963-26,952,256 & $18 \mathrm{q} 12.1$ & 0.68 & 7 & 0 & - & & \\
\hline Chr19:23,487,250-24,503,985 & 19p12-p11 & 1.02 & 7 & - & - & & \\
\hline Chr20:21,055,354-22,080,540 j & $\begin{array}{l}\text { 20p11.23- } \\
\text { p11.22 }\end{array}$ & 1.03 & 7 & $\mathrm{PAX}^{\mathrm{a}}$ & - & $(40)$ & $\begin{array}{c}20 \mathrm{p} 12.2- \\
\text { p11.23 }\end{array}$ \\
\hline Chr21:30,025,580-30,507,998 & $21 \mathrm{q} 21.3$ & 0.48 & 7 & USP16 ${ }^{\mathrm{a}}$ & - & & \\
\hline
\end{tabular}

${ }^{\mathrm{a}}$ Gene expressed in Metanephros, function not established. ${ }^{\mathrm{b}}$ Function shown in metanephros. ${ }^{\mathrm{c}}$ Non-coding RNA expressed mainly or only in kidney/urinary bladder. ${ }^{\mathrm{d} A c t i v a t e}$ the WNT signaling pathway. ${ }^{\mathrm{e}}$ Kidney specific, repairing damaged proteins. ${ }^{\mathrm{f}} \mathrm{Regulation}$ of ciliogenesis. ${ }^{\mathrm{g}}$ Activates STAT $1-3-5 .{ }^{\mathrm{h}} \mathrm{Kidney}$ specific, $\mathrm{Na} / \mathrm{K}$ regulation. ${ }^{\mathrm{i}}$ Interacts with TGFB and BMP. ${ }^{\mathrm{j} H a p l o t y p e s}$ were also found in analyses including one individual/family. (-) genes or non-coding RNA are present in the region, but are not known to be involved in kidney/urinary tract development. BMP3, Bone morphogenetic protein 3; FGF5, fibroblast growth factor 5; CEP290, centrosomal protein of $290 \mathrm{kDa}$; KITLG, Kit ligand; FREM2, FRAS1-related extracellular matrix 2; FOXA1, forkhead box A1; PLEK2, pleckstrin-2; SLC12A1, Solute carrier family 12 member 1; FBN1, fibrillin-1; PAX1, paired box protein; USP16, ubiquitin carboxyl-terminal hydrolase 16; TANKS, TRAF Family member associated NFKB activator; SLC9A6, solute carrier family 9 member A6. 


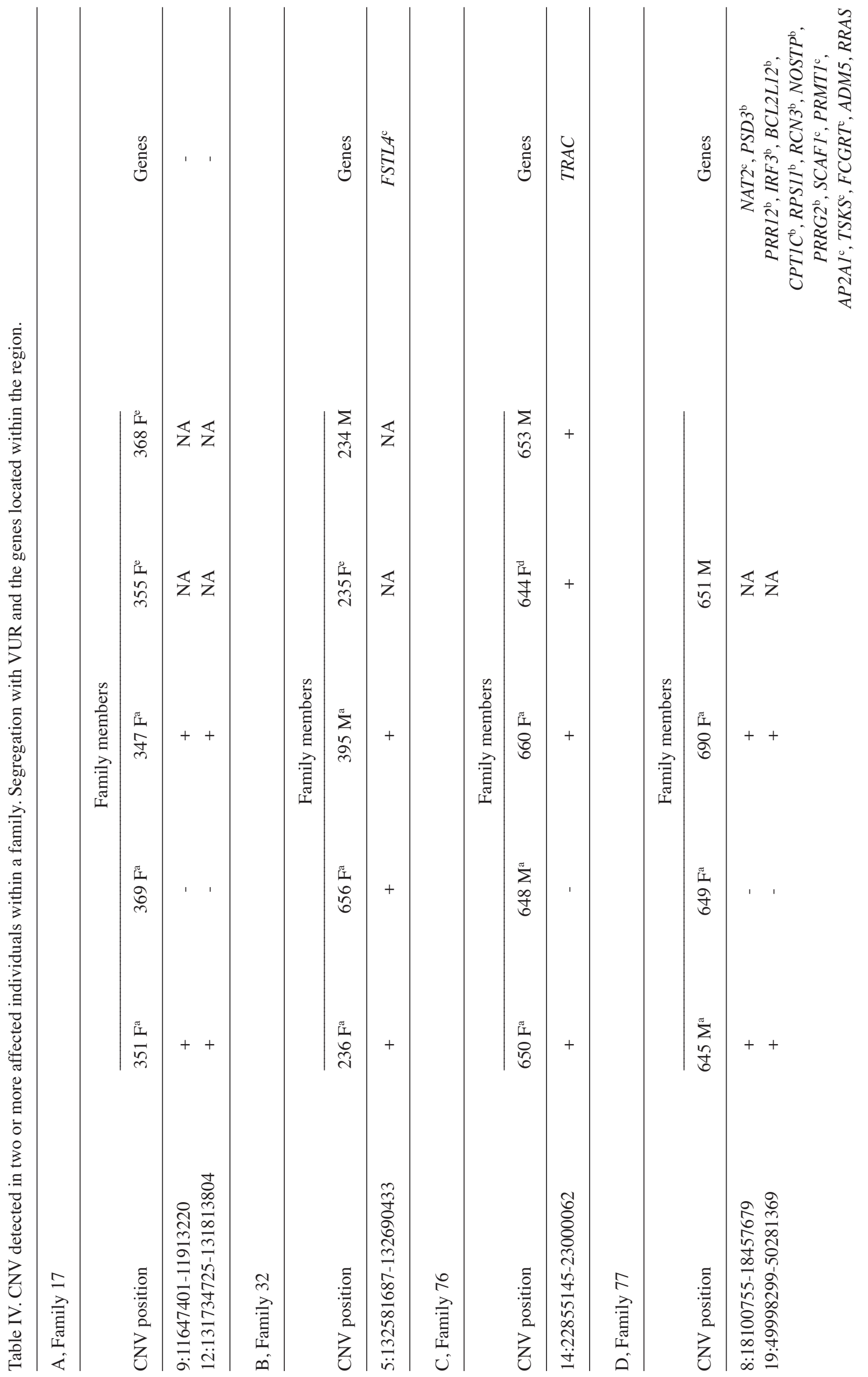




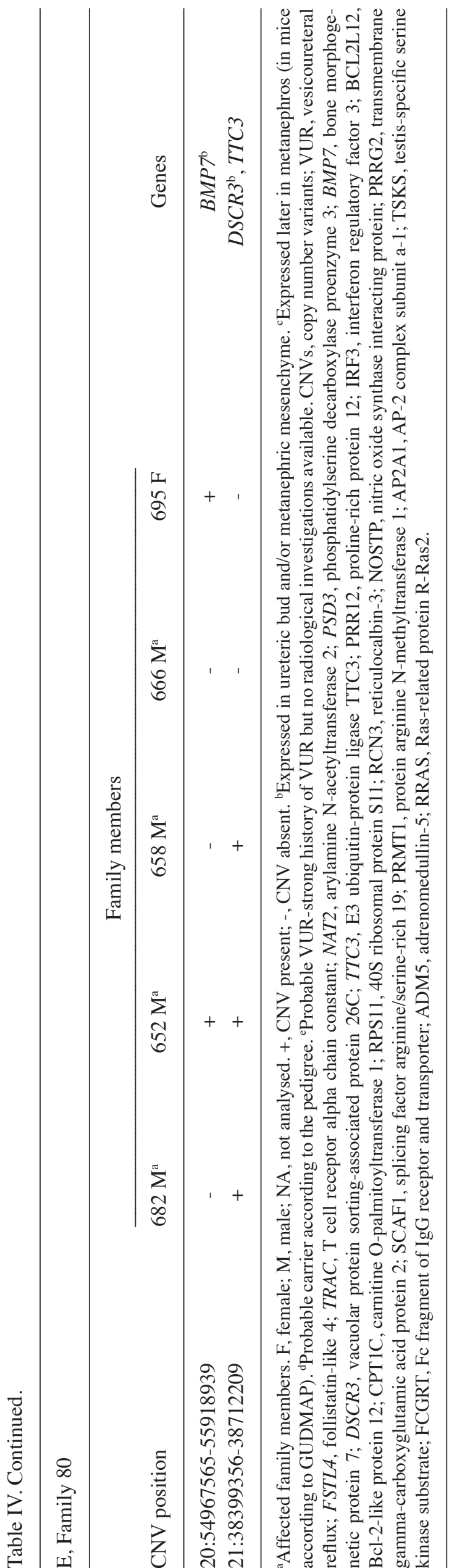

In these candidate regions where genes causing the disease might be located, we searched for coding and non-coding genes of interest in the embryological development of the kidney and UT. We differentiated between genes with a known function in the UB and MM, and genes only expressed in the metanephros according to GUDMAP but without known function (Table III). The haplotype region shared by the highest number of families $(n=10)$ and located at $4 p 15.1$ did not contain any protein coding elements. The non-coding RNAs were not expressed in the post-developmental kidney or UT, although to our knowledge their expression in the fetal kidney has not yet been investigated. A haplotype shared by nine families was also located on chromosome 4, at $4 \mathrm{q} 21.21$ (Table III). In this region, two tentative candidate genes were located; bone morphogenetic protein $3(B M P 3)$ in the middle of the region and fibroblast growth factor 5 (FGF5) at the lower end of the region, both with known functions in the embryological development of the kidney and UT. Non-coding RNAs were also present in this region, but with no known role in the post-developmental kidney.

Of the other four regions shared by nine families, two regions (12q21.32-q21.33 and 14q23.3) included genes with expression in metanephros, but without an identified function during kidney development (Table III). In the six haplotype regions shared by eight families no genes of interest were found. Of the 20 haplotypes shared by seven families each, one region on cytogenetic band 13q13.3 included the FRAS1 related extracellular matrix 2 (FREM2) gene with known functions in the embryonic kidney. Another locus at 14q13.3-21.1, contained the forkhead box A1 (FOXA1) gene, known to be involved in early embryological development of numerous organ systems. Of the remaining haplotypes shared by seven families, four included genes expressed in the embryological kidney, but without known function (Table III).

Non-coding RNA genes were present in almost all haplotype regions, often with detectable expression levels in most of the tissue samples, as presented by the GTExPortal (https://www.gtexportal.org/home/). A few lncRNA (14q13.3-q21.1 and 15q21.1, respectively), had expressions that were exclusive or almost exclusive to the post-natal kidney and UT. Despite extensive data mining regarding fetal expression of these lncRNA in the kidney (ENCODE-HaploReg 4.1), no available data could be found.

A large number of haplotype regions were shared by six families each (data not shown). A few genes of interest because of their roles in UB and MM development were located in these regions. One of these genes was ZFYVE9 at locus $1 \mathrm{p} 32.3$.

CNV analysis for locating inherited chromosomal imbalances. A large number of CNVs were detected in all the individuals analysed, with the overall CNV distribution (Fig. S1). We searched for recurrent identical CNVs within the families with $\log 2$ value $>0.2$ for gain and $\log 2<-0.2$ for loss. CNVs shared by several affected family members were detected in five families, although only one family (family 32) showed the presence of a shared CNV-a deletion at 5q31.1-in all affected relatives (Tables IV and SII). This chromosomal region contains the follistatin like 4 (FSTL4) gene, expressed during renal tubuli development, according to GUDMAP, but not detected in 


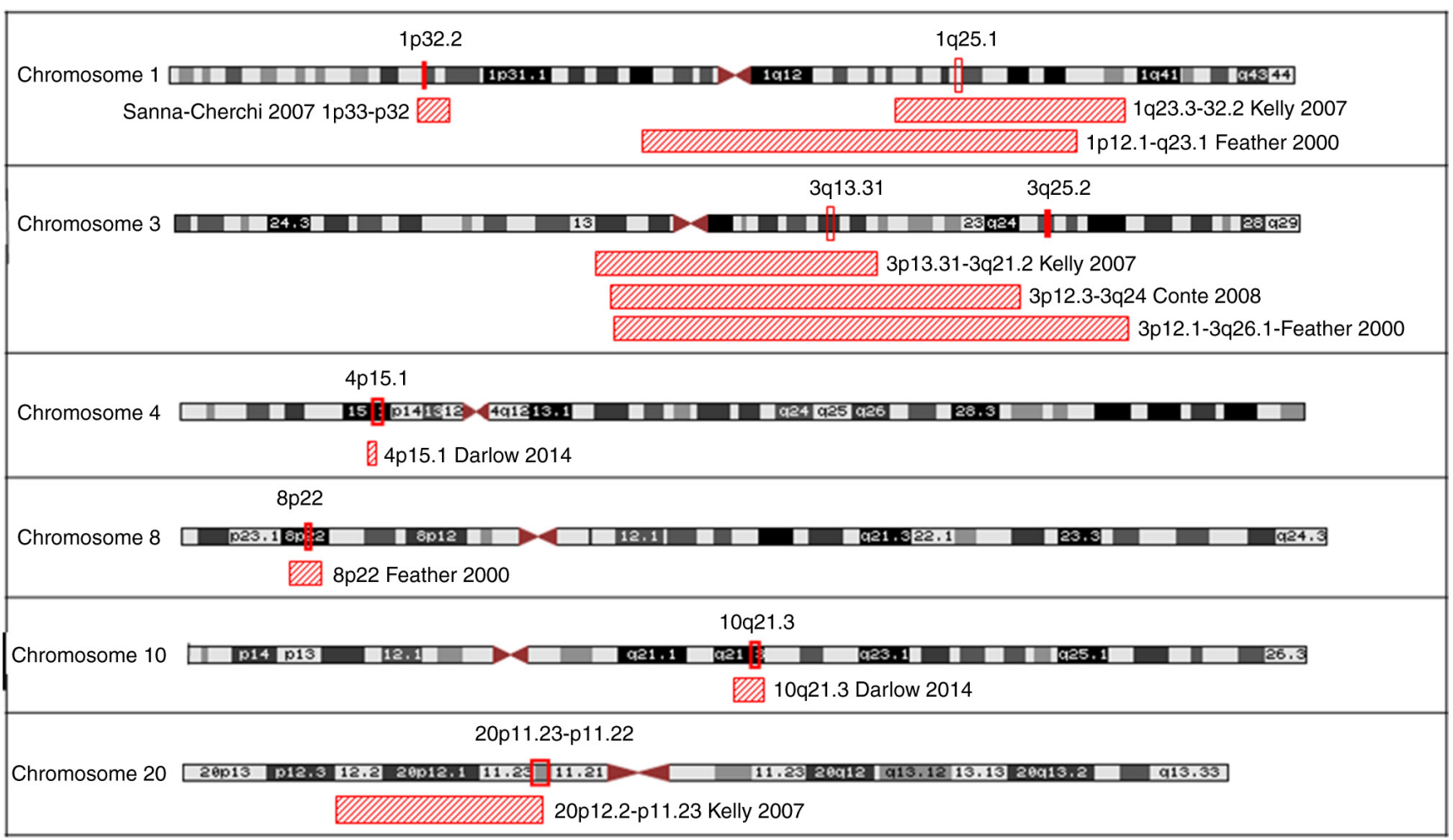

Figure 4. Haplotype regions shared by $\geq$ seven families in relation to previous studies. Common haplotypes in the general population have been excluded by the use of controls. Red boxes on the chromosomes and positions given above the chromosomes indicate results in the present study. Rectangles below the chromosome indicate results from previous studies. References are as follows: Sanna-Cherchi et al (35), Kelly et al (30), Feather et al (9), Darlow et al (31) and Conte et al (37).

earlier embryological phases (in UB or MM). An additional four CNVs were partially shared, meaning that some but not all affected family members were carriers of that specific CNV. Of specific interest is the duplication at 20q13.31, seen in family 80 . This region contains the $B M P 7$ gene, known to have a major function in kidney and UT development. However, it was only present in two family members. In addition, eighteen CNVs were shared by $\geq 2$ unrelated individuals among the families. Common CNVs in the population were excluded.

\section{Discussion}

There are numerous association and linkage studies, mainly genome-wide scans, searching for the chromosomal region(s) which can explain the heritability of VUR. These studies either include a large number of small families with $\geq 2$ affected members, often siblings (30-34), or a small number of large families with numerous cases $(9,11,35-37)$. They show few overlapping regions, posing the question of whether distinctive VUR-associated loci may vary in frequency in different populations. In our study, the pedigrees of the 14 families with three or more individuals with primary VUR indicate a dominant autosomal inheritance pattern with reduced penetrance, in line with earlier reports (8-11). Given their origin in a small homogenous region in Sweden, we wanted to investigate the possibility of shared ancestry among the families. We used a SNP compatibility matching method, a variant of linkage analysis, to analyse GWAS data. This data included only patients with the condition, taking an affected-only approach. This method was originally designed to detect a disease gene haplotype derived from a common ancestor, thus establishing a classical Mendelian dominant inheritance pattern $(23,24)$. However, in this case the method revealed that there was no haplotype region shared by all the affected members of the 14 families. This suggested that there was no common ancestral founder mutation, a finding in line with similar studies of other cohorts $(38,39)$.

Nevertheless, subsets of the VUR families were shown to share regions on candidate disease genes. In our study we have presented haplotype regions shared by seven or more families, and at least eight of our findings agreed with loci identified in other studies (on chromosomes 1, 3, 4, 8, 10 and 20, Fig. 4). The haplotype chromosomal region 4p15.1 was the region shared by most families $(n=10)$ and overlaps with a locus presented in an earlier case/control association study by Darlow et al (31). The region contained only non-coding genes, without any records of expression in the post-developmental kidney. Whether regulatory elements in this region fulfil functions in the fetal kidney is unknown and will require further study. Of the other novel haplotypes shared by several families in this present study, we found regions 4q21.21 ( $=9), 13 q 13.3(n=7)$ and 14q21.1 $(n=7)$ to be of particular interest given the current knowledge of the role of genes in fetal development of the kidney and UT. The 4q21.21 region contains $B M P 3$, encoding a ligand of the growth factor beta (GFB) superfamily with a role in organogenesis in embryonic kidney and renal tubuli development $(40,41)$. This chromosomal region also contains FGF5, which encodes for a member of the fibroblast growth and differentiation factor family, which in turn has been shown to have a role in metanephric development (42). Interaction between FGF and BMP signaling pathways has been shown to have a role 
in the regulation of MM development (43). Interestingly, in a patient with DiGeorge-like syndrome with unilateral renal agenesis and a deletion in chromosome 3, BMP3 was suggested as a target gene through action via the non-coding gene miRNA-4273 (44). The role of the BMP receptor family in VUR is further indicated by Darlow et al, which found an association with chromosomal region $4 \mathrm{q} 22.3$, which contains BMPR1B (31). The haplotype region 13q13.3 includes FREM2, which encodes a factor in the GDNF-RET/BMP signaling pathway, a factor that both affects expression and has an established function in the UB and MM. In addition, biallelic mutations in FREM2 cause the recessive disorder Fraser syndrome type 2, which includes CAKUT anomalies (45). The 14q21.1 haplotype includes FOXAl $(H N F 3 \alpha)$, a gene involved in early embryonic development in numerous organ systems. The gene is expressed in the embryonic kidney (metanephros) and UT, mainly in epithelia of the ureter. Nevertheless, studies in Foxal null mice did not show any overt malformations in the kidney. However, the condition led to death due to severe hypoglycaemia and dehydration, the latter due to nephrogenic diabetes insipidus $(46,47)$.

In the study of CNV inheritance in the 14 VUR families, only one family showed segregation of a CNV. This was a small deletion within chromosome 5q31.1, which included a part of FSTL4. This gene encodes a calcium ion-binding protein that is expressed during renal tubuli development, although not detected in earlier embryological phases (in UB or MM) according to GUDMAP. The 5q31.1-deletion was not present in the other families and has not been reported in previous publications $(21,22,48)$. Whereas the majority of the CNVs detected did not segregate fully with disease in the families, an overlap between our data and previously published findings of likely pathogenic de novo CNVs was seen in three loci; 7p22.1, 12q24 (21) and 8q24.13 (22). These latter studies included individuals with CAKUT, mainly renal hypodysplasia, which was also seen in the majority of our own patients. The CNV at 7p22.1 is associated with chromosome 7p interstitial duplication syndrome, which includes developmental delay and intellectual disability. However, the individual in our study who was found to have this duplication had neither kidney damage nor an extrarenal phenotype. The CNV at $12 \mathrm{q} 2$ was described as a large pathogenic de novo duplication associated with congenital kidney malformations (21).

Using GWA and the SNP compatibility matching method, we did not identify a unique haplotype IBD for all 14 families in the south-western part of Sweden with the VUR complex, although retained haplotypes were identified in subsets of families. However, a limitation of the present study was the small number of families with hereditary VUR, and also the limited number of generations included. The latter limitation was explained mainly by VUR being a radiological diagnosis not generally available before the 1970s, and thus the VUR diagnosis is not ideal for this type of studies of heredity far back. Nevertheless, partially shared haplotypes on chromosomes $4 \mathrm{q}$ and $13 \mathrm{q}$, with possible candidate genes, were retained as regions of interest after common haplotypes were eliminated. The genes identified in these regions have known functions in the embryogenesis of the kidney and UT but the regions also include non-coding genes. An overwhelming amount of data shows that the hereditary VUR-hypodysplasia complex is a genetically heterogeneous disease where less than
$10 \%$ of VUR patients have an identified pathogenic causal mutation (18). On the other hand, knowledge of non-coding regulatory elements and their expression in the UB and MM at the time points when the VUR anomaly develops, is currently very limited and thus a limitation of the study. However, this is an emerging field that aids in the identification of regulatory elements in the human genome and makes possible the potential discovery of new mechanisms which govern VUR.

\section{Acknowledgements}

Mrs. Alice Andersson and Mrs Eva Johansson (The Queen Silvia Children's Hospital, Gothenburg, Sweden) assisted in collecting patient information, samples and data from medical records.

\section{Funding}

The present study was financed by grants from the Swedish state under the agreement between the Swedish Government and county councils, the ALF agreement (grant no. ALFGBG-830501).

\section{Availability of data and materials}

The datasets used and/or analyzed during the current study are available from the corresponding author on reasonable request.

\section{Authors' contributions}

ZB, US, TM, MÖ and SF designed the study. AD, RS and ZB collected the material and performed the SNP genotyping. MÖ carried out SNP compatibility matching through advanced statistical analysis. TM, MÖ and SF confirm the authenticity of all the raw data. All authors have read and approved the final manuscript.

\section{Ethics approval and consent of participants}

The Regional Ethical Review Board in Gothenburg approved the study (approval no. Dnr 589-05). Written informed consent was obtained from all patients.

\section{Patient consent for publication}

Not applicable.

\section{Competing interests}

The authors declare that they have no competing interests.

\section{References}

1. Sargent MA: What is the normal prevalence of vesicoureteral reflux? Pediatr Radiol 30: 587-593, 2000.

2. Yeung CK, Godley ML, Dhillon HK, Gordon I, Duffy PG and Ransley PG: The characteristics of primary vesico-ureteric reflux in male and female infants with pre-natal hydronephrosis. Br J Urol 80: 319-327, 1997.

3. Peters C and Rushton HG: Vesicoureteral reflux associated renal damage: Congenital reflux nephropathy and acquired renal scarring. J Urol 184: 265-273, 2010.

4. Noe HN, Wyatt RJ, Peeden JN Jr and Rivas ML: The transmission of vesicoureteral reflux from parent to child. J Urol 148: 1869-1871, 1992 
5. Jerkins GR and Noe HN: Familial vesicoureteral reflux: A prospective study. J Urol 128: 774-778, 1982.

6. Wan J, Greenfield SP, Ng M, Zerin M, Ritchey ML and Bloom D: Sibling reflux: A dual center retrospective study. J Urol 156: 677-679, 1996

7. Parekh DJ, Pope JC IV, Adams MC and Brock JW III: Outcome of sibling vesicoureteral reflux. J Urol 167: 283-284, 2002.

8. Chapman CJ, Bailey RR, Janus ED, Abbott GD and Lynn KL: Vesicoureteric reflux: Segregation analysis. Am J Med Genet 20: $577-584,1985$

9. Feather SA, Malcolm S, Woolf AS, Wright V, Blaydon D, Reid CJ, Flinter FA, Proesmans W, Devriendt K, Carter J, et al: Primary, nonsyndromic vesicoureteric reflux and its nephropathy is genetically heterogeneous, with a locus on chromosome 1 . Am J Hum Genet 66: 1420-1425, 2000.

10. Eccles MR and Jacobs GH: The genetics of primary vesico-ureteric reflux. Ann Acad Med Singap 29: 337-345, 2000

11. Sanna-Cherchi S, Reese A, Hensle T, Caridi G, Izzi C, Kim YY, Konka A, Murer L, Scolari F, Ravazzolo R, et al: Familial vesicoureteral reflux: Testing replication of linkage in seven new multigenerational kindreds. J Am Soc Nephrol 16: 1781-1787, 2005.

12. Lu W, van Eerde AM, Fan X, Quintero-River F, Kulkarni S Ferguson H, Kim HG, Fan Y, Xi Q, Li QG, et al: Disruption of ROBO2 is associated with urinary tract anomalies and confers risk of vesicoureteral reflux. Am J Hum Genet 80: 616-632, 2007

13. Weng PL, Sanna-Cherchi S, Hensle T, Shapiro E, Werzberger A Caridi G, Izzi C, Konka A, Reese AC, Cheng R, et al: A recessive gene for primary vesicoureteral reflux maps to chromosome 12p11-q13. J Am Soc Nephrol 20: 1633-1640, 2009.

14. Naseri M, Ghiggeri GM, Caridi G and Abbaszadegan MR: Five cases of severe vesico-ureteric reflux in a family with an X-linked compatible trait. Pediatr Nephrol 25: 349-352, 2010.

15. Fillion ML, Watt CL and Gupta IR: Vesicoureteric reflux and reflux nephropathy: From mouse models to childhood disease. Pediatr Nephrol 29: 757-766, 2014

16. Ichikawa I, Kuwayama F, Pope JC IV, Stephens FD and Miyazaki Y: Paradigm shift from classic anatomic theories to contemporary cell biological views of CAKUT. Kidney Int 61: 889-898, 2002.

17. Nicolaou N, Pulit SL, Nijman IJ, Monroe GR, Feitz WF, Schreuder MF, van Eerde AM, de Jong TP, Giltay JC, van der Zwaag B, et al: Prioritization and burden analysis of rare variants in 208 candidate genes suggest they do not play a major role in CAKUT. Kidney Int 89: 476-486, 2016.

18. Hwang DY, Dworschak GC, Kohl S, Saisawat P, Vivante A Hilger AC, Reutter HM, Soliman NA, Bogdanovic R, Kehinde EO, et al: Mutations in 12 known dominant disease-causing genes clarify many congenital anomalies of the kidney and urinary tract. Kidney Int 85: 1429-1433, 2014.

19. Kleinjan DA and van Heyningen V: Long-range control of gene expression: Emerging mechanisms and disruption in disease. Am J Hum Genet 76: 8-32, 2005

20. Southard AE, Edelmann LJ and Gelb BD: Role of copy number variants in structural birth defects. Pediatrics 129: 755-763, 2012

21. Sanna-Cherchi S, Kiryluk K, Burgess KE, Bodria M,Sampson MG Hadley D, Nees SN, Verbitsky M, Perry BJ, Sterken R, et al Copy-number disorders are a common cause of congenital kidney malformations. Am J Hum Genet 91: 987-997, 2012.

22. Caruana G, Wong MN, Walker A, Heloury Y, Webb N, Johnstone L, James PA, Burgess T and Bertram JF: Copy-number variation associated with congenital anomalies of the kidney and urinary tract. Pediatr Nephrol 30: 487-495, 2015

23. Ohlsson M, Hedberg C, Bradvik B, Lindberg C, Tajsharghi H, Danielsson O, Melberg A, Udd B, Martinsson T and Oldfors A: Hereditary myopathy with early respiratory failure associated with a mutation in A-band titin. Brain 135: 1682-1694, 2012.

24. Östensson M: Statistical Methods for Genome Wide Association Studies. PhD dissertation, University of Gothenburg. ISBN, 9789173857420, 2012

25. Piepsz A, Colarinha P, Gordon I, Hahn K, Olivier P, Roca I, Sixt R and van Velzen J; Paediatric Committee of the European Association of Nuclear Medicine: Guidelines for 99mTc-DMSA scintigraphy in children. Eur J Nucl Med 28: BP37-BP41, 2001.

26. Schwartz GJ, Brion LP and Spitzer A: The use of plasma creatinine concentration for estimating glomerular filtration rate in infants, children, and adolescents. Pediatr Clin North Am 34: 571-590, 1987

27. Brochner-Mortensen J, Haahr J and Christoffersen J: A simple method for accurate assessment of the glomerular filtration rate in children. Scand J Clin Lab Invest 33: 140-143, 1974.

28. Bengtsson H, Wirapati P and Speed TP: A single-array preprocessing method for estimating full-resolution raw copy numbers from all Affymetrix genotyping arrays including GenomeWideSNP 5 \& 6. Bioinformatics 25: 2149-2156, 2009.
29. Olshen AB, Venkatraman ES, Lucito R and Wigler M: Circular binary segmentation for the analysis of array-based DNA copy number data. Biostatistics 5: 557-572, 2004

30. Kelly H, Molony CM, Darlow JM,Pirker ME, Yoneda A, Green AJ, Puri P and Barton DE: A genome-wide scan for genes involved in primary vesicoureteric reflux. J Med Genet 44: 710-717, 2007.

31. Darlow JM, Dobson MG, Darlay R, Molony CM, Hunziker M, Green AJ, Cordell HJ, Puri P and Barton DE: A new genome scan for primary nonsyndromic vesicoureteric reflux emphasizes high genetic heterogeneity and shows linkage and association with various genes already implicated in urinary tract development. Mol Genet Genomic Med 2: 7-29, 2014

32. Marchini GS, Onal B, Guo CY, Rowe CK, Kunkel L, Bauer SB, Retik AB and Nguyen HT: Genome gender diversity in affected sib-pairs with familial vesico-ureteric reflux identified by single nucleotide polymorphism linkage analysis. BJU Int 109: 1709-1714, 2012

33. Cordell HJ, Darlay R, Charoen P, Stewart A, Gullett AM, Lambert HJ, Malcolm S, Feather SA, Goodship TH, Woolf AS, et al: Whole-genome linkage and association scan in primary, nonsyndromic vesicoureteric reflux. J Am Soc Nephrol 21: 113-123, 2010.

34. Briggs CE, Guo CY, Schoettler C, Rosoklija I, Silva A, Bauer SB Retik AB, Kunkel L and Nguyen HT: A genome scan in affected sib-pairs with familial vesicoureteral reflux identifies a locus on chromosome 5. Eur J Hum Genet 18: 245-250, 2010.

35. Sanna-Cherchi S, Caridi G, Weng PL, Dagnino M, Seri M, Konka A, Somenzi D, Carrea A, Izzi C, Casu D, et al: Localization of a gene for nonsyndromic renal hypodysplasia to chromosome 1p32-33. Am J Hum Genet 80: 539-549, 2007.

36. Casas KA, Mononen TK, Mikail CN, Hassed SJ, Li S, Mulvihill JJ, Lin HJ and Falk RE: Chromosome $2 q$ terminal deletion: Report of 6 new patients and review of phenotype-breakpoint correlations in 66 individuals. Am J Med Genet A 130A: 331-339, 2004

37. Conte ML, Bertoli-Avella AM, de Graaf BM, Lama G, La Manna A, Grassia C, Rambaldi PF, Oostra BA, Perrotta S and Punzo F: A genome search for primary vesicoureteral reflux shows further evidence for genetic heterogeneity. Pediatr Nephrol 23: 587-595, 2008

38. Williams G, Fletcher JT, Alexander SI and Craig JC: Vesicoureteral reflux. J Am Soc Nephrol 19: 847-862, 2008

39. Carvas F, Silva A and Nguyen HT: The genetics of primary, nonsyndromic vesicoureteral reflux. Curr Opin Urol 20: 336-342, 2010.

40. Vukicevic S, Helder MN and Luyten FP: Developing human lung and kidney are major sites for synthesis of bone morphogenetic protein-3 (osteogenin). J Histochem Cytochem 42: 869-875, 1994.

41. Takahashi $\mathrm{H}$ and Ikeda T: Transcripts for two members of the transforming growth factor-beta superfamily BMP-3 and BMP-7 are expressed in developing rat embryos. Dev Dyn 207: 439-449, 1996.

42. Cancilla B, Ford-Perriss MD and Bertram JF: Expression and localization of fibroblast growth factors and fibroblast growth factor receptors in the developing rat kidney. Kidney Int 56: 2025-2039, 1999

43. Dudley AT, Godin RE and Robertson EJ: Interaction between FGF and BMP signaling pathways regulates development of metanephric mesenchyme. Genes Dev 13: 1601-1613, 1999.

44. Cirillo E, Giardino G, Gallo V, Galasso G, Romano R, D'Assante R, Scalia G, Del Vecchio L, Nitsch L, Genesio R and Pignata C: DiGeorge-like syndrome in a child with a 3p12.3 deletion involving MIR4273 gene born to a mother with gestational diabetes mellitus. Am J Med Genet A 173: 1913-1918, 2017.

45. Kohl S, Hwang DY, Dworschak GC, Hilger AC, Saisawat P, Vivante A, Stajic N, Bogdanovic R, Reutter HM, Kehinde EO, et al: Mild recessive mutations in six Fraser syndrome-related genes cause isolated congenital anomalies of the kidney and urinary tract. J Am Soc Nephrol 25: 1917-1922, 2014.

46. Bernardo GM and Keri RA: FOXA1: A transcription factor with parallel functions in development and cancer. Biosci Rep 32: 113-130, 2012.

47. Kaestner KH: The FoxA factors in organogenesis and differentiation. Curr Opin Genet Dev 20: 527-532, 2010

48. Siomou E, Mitsioni AG, Giapros V, Bouba I, Noutsopoulos D and Georgiou I: Copy-number variation analysis in familial nonsyndromic congenital anomalies of the kidney and urinary tract: Evidence for the causative role of a transposable element-associated genomic rearrangement. Mol Med Rep 15: 3631-3636, 2017.

This work is licensed under a Creative Commons Attribution-NonCommercial-NoDerivatives 4.0 International (CC BY-NC-ND 4.0) License. 